\title{
Short Communication: Variations of morphology, anatomy, and metabolite profiles of Citrus reticulata Blanco cv. Tawangmangu grafts produced by shoot tip grafting using several rootstocks
}

\author{
EINSTIVINA NURYANDANI ${ }^{1,2}$, RATNA SUSANDARINI ${ }^{1, \vartheta}$, ARI INDRIANTO ${ }^{1, R I P}$, TRI RINI NURINGTYAS ${ }^{1}$, \\ ARTNICE MEGA FATHIMA ${ }^{3}$, SITI SUBANDIYAH ${ }^{3,4}$ \\ ${ }^{1}$ Graduate Program, Faculty of Biology, Universitas Gadjah Mada. Jl. Teknika Selatan, Sekip Utara, Sleman 55281, Yogyakarta, Indonesia \\ Tel./fax.: +62-274-580839, `email: ratna-susandarini@ugm.ac.id \\ ${ }^{2}$ Faculty of Science and Technology, Universitas Terbuka. Jl. Cabe Raya, Pondok Cabe, Pamulang, Tangerang Selatan 15437, Banten, Indonesia \\ ${ }^{3}$ Research Center of Biotechnology, Universitas Gadjah Mada. Jl. Teknika Utara, Sleman 55281, Yogyakarta, Indonesia \\ ${ }^{4}$ Faculty of Agriculture, Universitas Gadjah Mada. Jl. Flora, Bulaksumur, Sleman 55281, Yogyakarta, Indonesia
}

Manuscript received: 20 August 2020. Revision accepted: 19 September 2020.

\begin{abstract}
Nuryandani E, Susandarini R, Indrianto A, Nuringtyas RT, Fathima AM, Subandiyah S. 2020. Short Communication: Variations of morphology, anatomy, and metabolite profiles of Citrus reticulata Blanco cv. Tawangmangu grafts produced by shoot tip grafting using several rootstocks. Biodiversitas 21: 4671-4676. Cultivation of Citrus reticulata Blanco cv. Tawangmangu, one of leading mandarin cultivars in Indonesia, remains challenging due to the limitations of suitable rootstocks. The use of suitable rootstocks will greatly determine the success of grafting and affect the performance of the scion. This study aimed to evaluate the morphological, anatomical, and metabolic profiles of grafts between Tawangmangu and rootstocks from various species using shoot tip grafting. Observations of morphological, anatomical, and metabolite variation were carried out eight weeks after the beginning of the growth of the scions. The morphological characters were observed on leaves and stems of the scions. Anatomical data were obtained from the examination of longitudinal sections of grafts prepared using paraffin-embedded method. Analysis of metabolite profiles was performed using LC-MS. The results showed that for two of the three rootstocks used, C. ichangensis $\times$ C. reticulata cv. Austera (Japansche Citroen (JC)) and Citrus (Fortunella) japonica (Fortunella) scion growth was vigorous and resulted in a large number of leaves and long stems. Morphological variation was found in the leaf shape, as indicated by wider and wavy leaves of grafts with Fortunella, while narrower and straighter leaves were found in grafts with JC. The grafting onto the third rootstock, $C$. hystrix, induced dwarfing of the scions. Variation in the anatomical profiles was found in vascular vessels, and in exodermic and endodermic cell sizes. Differences in metabolic profiles of the grafts were found compared to scion and rootstocks. Results of this study provide an important contribution to the successful improvement of Tawangmangu.
\end{abstract}

Keywords: Cultivar selection, growth performance, mandarin orange, physiological interactions

\section{INTRODUCTION}

Citrus production in Indonesia has not been able to meet the domestic demand and the expected additional income. This situation promotes the exploration of potential Citrus species and cultivars for selection programs to improve the yield and the subsequent income (De-Miguel et al. 2019). Citrus reticulata cv. Tawangmangu (mandarin group) is one of the leading citrus commodities in Indonesia. However, the cultivation of this cultivar remains challenging, since the limitations of suitable rootstocks.

Grafting is widely used for horticultural tree crops (Assunção et al. 2016; Prodhomme et al. 2019). Citrus and other commercial fruit trees are usually cultivated as grafted trees with a selected rootstock. This technique offers many benefits including an increase in product quality and yield (Vršič et al. 2016), increase the resistance against pathogens and abiotic stresses (Ramírez-Gil 2018; Zhou et al. 2018), reductions in the period to fruiting through increasing precocity, avoidance of a juvenile state (Baron et al. 2019), and gain specific characters from the scion such as dwarfing to facilitate maintenance and harvesting (Hartmann et al. 2011).

Shoot tip grafting (STG) can minimize the contamination of pathogens in scion/rootstock combinations and provide suitable environmental conditions for successful grafting (Navarro and Juarez 2007; Singh et al. 2019). This technique is vital to make an obvious and distinctive comparison of scions changes. Troyer citrange is the most common rootstock used in STG (Navarro and Juarez 2007), whereas in Indonesia, the common rootstock used for STG is Japansche Citroen (JC) (Agus and Eka 2017). Even though several other rootstocks are available and may have better performance, their applications are rarely evaluated.

Several changes in scion growth due to the use of different rootstocks have been recorded in previous studies. These scion-rootstock interactions lead to changes in morphology (Hartmann 2011), leaf metabolites (Killiny et 
al. 2018), and fruit juice and phloem sap (Tietel et al. 2019). These changes can be mistaken with the responses from environmental traits in field trials (Kimura et al. 2017) or the occurrence of pathogens (Albrecht et al. 2016). A number of studies have been performed to examine variation due to grafting and the roles of rootstocks on grafts, and the interactions were found to be specific for a particular species or cultivar (Hartmann et al. 2011).

This study was conducted to examine variations in morphological, anatomical, and metabolite profiles of $C$. reticulata $\mathrm{cv}$. Tawangmangu grafts produced from shoot tip grafting with Japansche Citroen, Fortunella, and C. hystrix. The results of this study are essential for rootstock selection to generate composite plants with good growth performance.

\section{MATERIALS AND METHODS}

\section{Shoot tip grafting}

STG was performed according to the procedure of Navarro and Juarez (2007) with slight modifications. Two week-old, in vitro-grown seedlings (30-50 mm height) of C. ichangensis $\times$ C. reticulata cv. Austera (Japansche Citroen (JC)), Citrus (Fortunella) japonica (Fortunella), and $C$. hystrix were used as the rootstocks; $C$. reticulata $\mathrm{cv}$. Tawangmangu (autograft) was included as the control.

Scions of Tawangmangu were taken from the branches of actively growing plants. New shoots of $30 \mathrm{~mm}$ long were collected and taken to the laboratory in a moist bag. The leaves were removed and the shoot tips were cut to give $10 \mathrm{~mm}$ lengths. The shoot tips were then sterilized by soaking in $0.26 \%$ sodium hypochlorite with 3 drops of Tween $^{\mathrm{TM}}$ for $5 \mathrm{~min}$ and then rinsed 2-3 times in sterile distilled water.

The cotyledons and axillary meristems of the in vitro grown rootstock seedlings were removed aseptically, and the roots were trimmed to $40-60 \mathrm{~mm}$ lengths below the stem. The epicotyls were cut about $15-20 \mathrm{~mm}$ from the cotyledons and then incised with an inverted $\mathrm{T}$ incision, made by a $1 \mathrm{~mm}$ long vertical incision, starting at the point of decapitation, and a 1-2-mm-wide horizontal cut. The incision was made until it reached the cortex and the lid of the incision was raised slightly to expose the cortex. The tips $(0.5-0.7 \mathrm{~mm})$ of the scions were aseptically cut under a stereo microscope or magnifying glass. The grafting was carried out by placing the cut-end of the shoot at the center of the incision, attached to the cortex.

The grafts were cultured in Murashige-Skoog (MS) liquid medium containing White's vitamins and supplemented with $7.5 \%$ sucrose and incubated at $21 \pm 2^{\circ} \mathrm{C}$. For the first two days, the grafts were incubated in the dark and then they were illuminated with 1000 lux. For each rootstock, nine replications were made. Observations of morphology, anatomy, and metabolite profiles were performed eight weeks after grafting.

\section{Morphological observation}

Qualitative parameters observed for scion growth on different rootstocks included leaf and stem morphology.

\section{Anatomical observation}

Eight-week-old successful grafts were excised and softened in $70 \%$ ethanol. The samples were then dehydrated in an ethanol series $(70,80,95,100 \%)$ for 30 min each. Clearing was performed in an ethanol:xylol series $(3: 1 ; 1: 1 ; 1: 3 ; 0: 1)$. Specimens were then embedded in paraffin wax after infiltration in $1 \%$ safranin. Samples were sectioned at a thickness of 6-12 $\mu \mathrm{m}$ using a sliding microtome. Finally, the graft sections were observed using an Olympus $\mathrm{CH}-\mathrm{BI} 45-2$ light microscope at magnifications of $40 \times$ and $100 \times$ and then captured using an OptiLab microscope camera.

\section{Metabolic profiling analysis}

Eight-week-old leaves and branches from the scions of successful grafts and from the rootstocks were harvested and air-dried. The samples were then powdered using liquid nitrogen and immersed in 10\% methanol (1:10 (v/v)) in distilled water for $24 \mathrm{~h}$, filtered, and then air-dried. The extraction using methanol was repeated twice. The dried samples were then analyzed by using liquid chromatography-mass spectrometry (LC-MS) using a Thermo Scientific Q Exactive Hybrid Quadrupole-Orbitrap mass spectrometer with a full scan at 70,000 resolution. Polyphenol resolution was performed with two kinds of solvents, $\mathrm{A}=0.1 \%$ formic acid in water and $\mathrm{B}=0.1 \%$ formic acid in acetonitrile. The analytical column used for this analysis was a Hypersil GOLD aQ $(50 \times 1 \mathrm{~mm}$, particle size $1.9 \mu \mathrm{m}$ ) with an analytical flow rate of 40 $\mu \mathrm{L} / \mathrm{min}$. Data processing was done using Compound Discoverer software with the mzCloud MS/MS Library.

\section{RESULTS AND DISCUSSION}

\section{Morphological observations}

Morphological variation was found in the growth of scions including differences in leaf and stem shapes and sizes. Scions on Fortunella produced the best growth compared to those on other rootstocks (Figure 1). The leaves of the scions on Fortunella developed quickly, were not malformed, and had a larger size than leaves of the scions on the other rootstocks. The scions on JC had a similar number of leaves to the autograft but were of smaller size, while the scions on $C$. hystrix only produced small numbers of leaves that were small in size (Figures 1 and 2). 


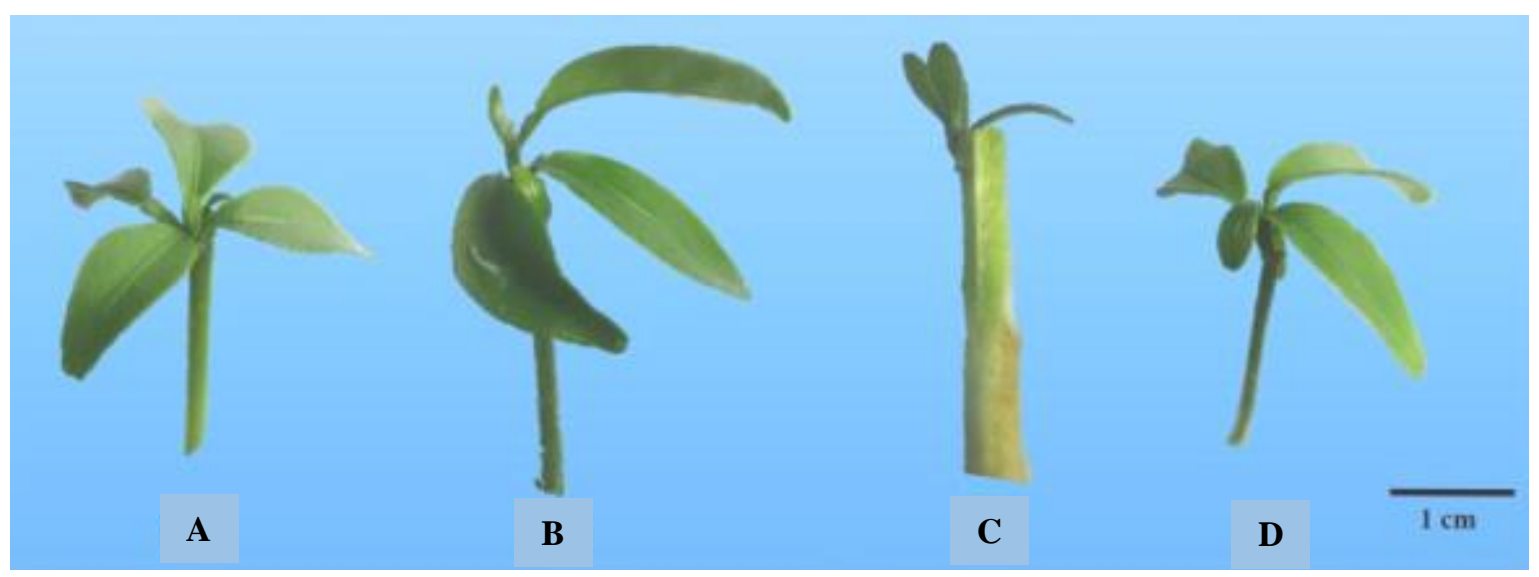

Figure 1. Growth of the scions of Tawangmangu 8 weeks after grafting on to: A. JC, B. Fortunella, C. C. hystrix, and D. Tawangmangu. Scale bar $=1 \mathrm{~cm}$

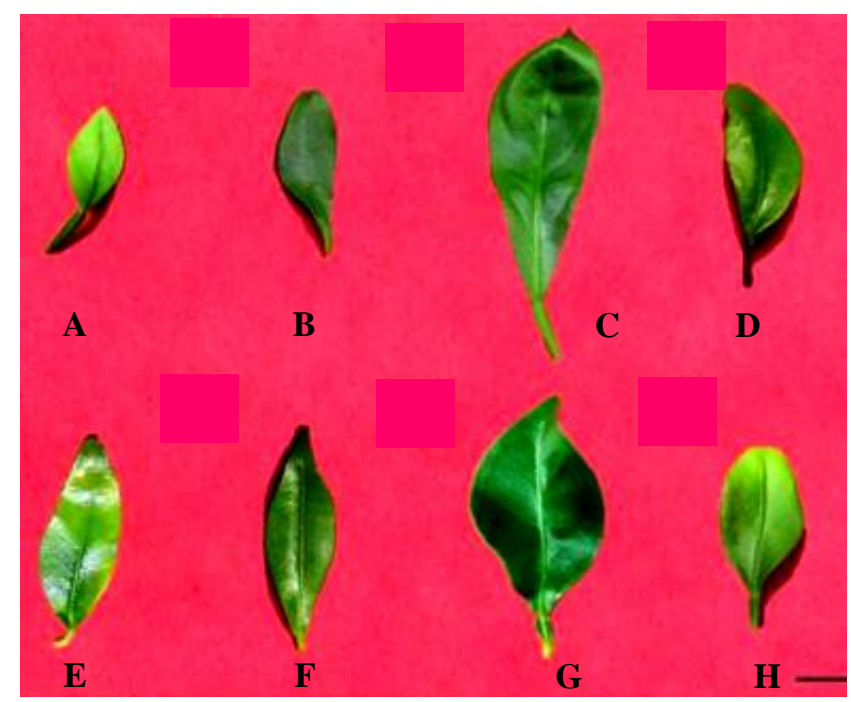

Figure 2. Morphological variation in leaf shape and size of rootstocks (A-D) and scions (E-H): A. C. hystrix, B. JC, C. Fortunella, D. Tawangmangu and grafts of Tawangmangu on E. C. hystrix, F. JC, G. Fortunella, and H. Tawangmangu. Scale bar $=5 \mathrm{~mm}$

Stem growth of the scions on JC, Fortunella, and Tawangmangu was quite good and of a reasonably long size. This result differed from the scions on $C$. hystrix which did not undergo lengthening and were dwarfed (Figure 1). Differences in sizes of composite plants are one of the most significant effects of rootstocks (Hartmann et al. 2011). According to a study on apple rootstocks, the degree of vigor of the scions can be divided into dwarfing, semidwarfing, vigorous, and very vigorous growth (Hartmann et al. 2011). Compared to control grafts, the growth of grafts with Fortunella was categorized as very vigorous. Grafts with JC were classified as vigorous, because they showed similar growth characteristics to the control, while those with $C$. hystrix were categorized as dwarfed.
The leaves of Fortunella had the largest size compared to those of other rootstocks. The leaves of JC and C. hystrix were notably narrower (Figure 2). The scions on Fortunella and Tawangmangu had broad leaves, whereas the leaves of the scions on JC and $C$. hystrix tended to be narrow and slightly elongated. The leaves of Fortunella had characteristic of curved edges and showed some degree of similarity to Tawangmangu, although the curvature was not specifically at the edges.

To some extent, the characteristics of the leaves of the rootstocks were seen in the growth of the leaves of the scions grafted onto them, as found in the leaves of the Tawangmangu grafted on the Fortunella which had broad and curved leaves. However, they were not exactly the same as those of the rootstock, which were notched at the edges. The morphological characters of Tawangmangu leaves which were grafted on to the same rootstock species had almost the same characteristics as those of the original rootstock. In addition, the scions on JC had relatively narrow, elongated, and slightly curved leaves, nearly the same as those of the leaves of the scions on C. hystrix.

Specific rootstocks may cause changes in a graft's shape (Hartmann et al. 2011). In this study, we observed that the morphological properties of rootstock's leaves greatly influenced the morphology of the leaves of the scions grafted onto them (Figure 2). Similar results have been reported by Kudo and Harada (2007) on grafts between potato (Solanum tuberosum) as the scion and tomato (Lycopersicon esculentum) as the rootstock, in which grafting altered the leaf morphology of the scions due to a graft-transmissible RNA. In another study on the grafting of Acacia mellifera and A. senegal as scions onto A. polyacantha and $A$. seyal as the rootstocks, Eltayb et al. (2014) showed that grafting changed the leaves, branches, stem, thorns, and fruit morphology of the scions.

\section{Anatomical examinations}

Anatomical observations of the grafts on JC, Fortunella $C$. hystrix, and Tawangmangu were carried out on longitudinal sections of the scions (Figure 3). 

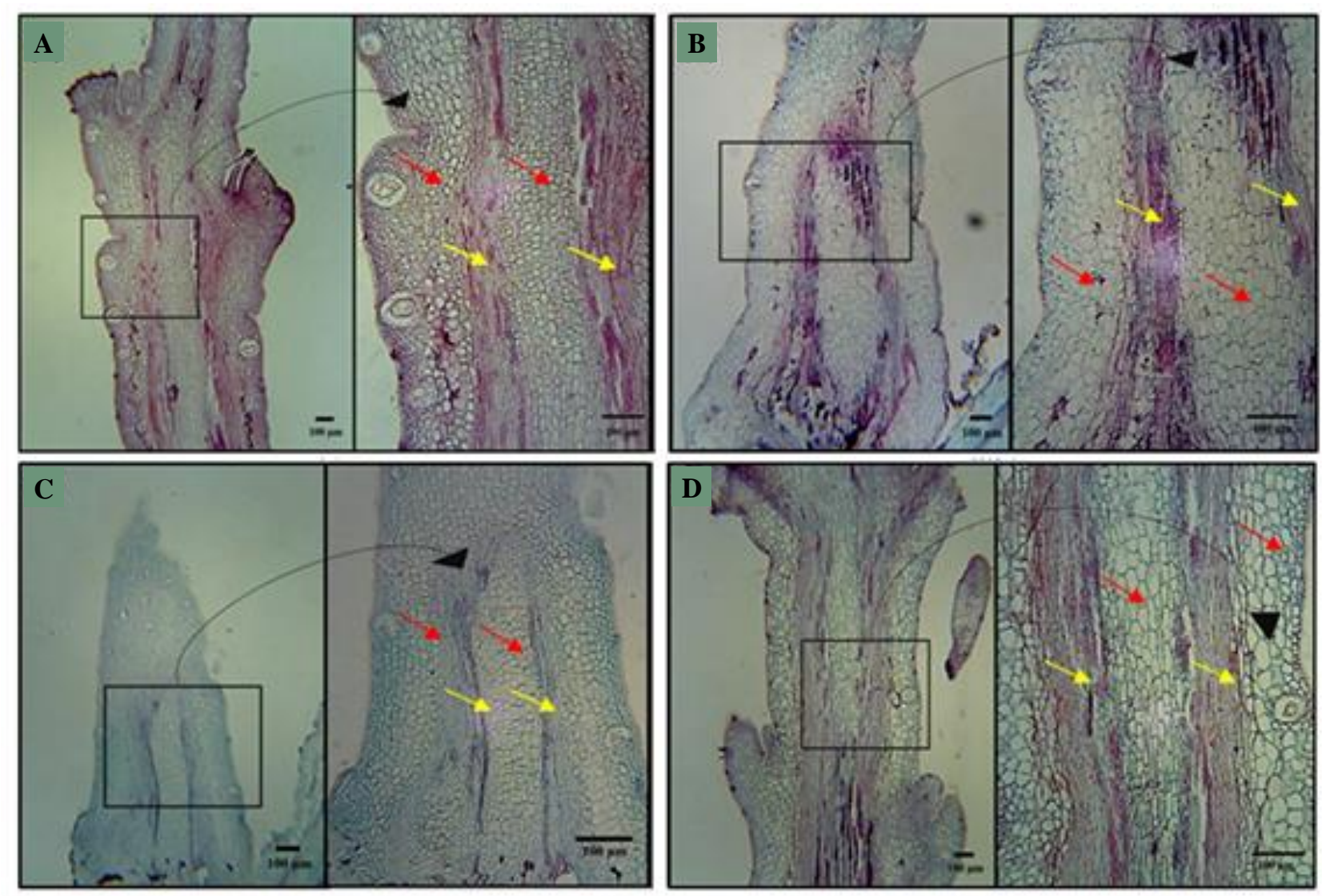

Figure 3. The anatomical structure of grafts of Tawangmangu with the rootstocks: A. JC, B. Fortunella, C. C. hystrix, and D. Tawangmangu. Vascular vessel development is indicated by yellow arrows. Ectoderm and endoderm cells are indicated by red arrows.

The sizes of the stems of the scion grafted on to $C$. hystrix were short in comparison to the control graft and the graft with the other two rootstocks. Another clear difference was the size of the vascular vessels which were quite narrow when compared to the control and the two grafts on JC and Fortunella that had relatively wide vessel sizes. Vessel size and number of vessels are related to dwarfism (de Carvalho et al. 2018). This obvious difference in vascular vessel width may explain why the growth of the scions on $C$. hystrix was dwarfed. The smallsize phenomena might be related to the function of the vascular vessels, which is quite crucial in graft growth by transporting photoassimilates from the scion to rootstock (via phloem) and the transport of water, minerals, and nutrients from the rootstock to the scion. Important signaling molecules for growth are also transported by this tissue (Nanda and Melnyk 2017). Findings from Foster et al. (2017) indicated that dwarfed composite plants were in a state of sugar depletion and had reduced cellular activity despite having large starch reserves. Moreover, the abovementioned study noted that a reduction of polar auxin transport occurs in dwarf plants.

Another variation observed in the scions was differences in cell size, both in the endodermis and the exodermis. The cells in the scions on JC and $C$. hystrix were small and compactly arranged, while the cells in the grafts with Fortunella and control were relatively large and broad in shape. These characters were in line with results on the observation of leaf morphology. The leaves of the scions on JC and $C$. hystrix had a narrow shape, while the leaf shape in the control and Fortunella have a broad shape. It is unclear whether both characters were related one to another, since there were no comparable studies that could be referred to. In contrary to these findings, histological analysis by He et al. (2018) on graft combinations of Citrus grandis indicated that there were no significant anatomical differences between different grafts combinations.

\section{Analysis of metabolic profiles}

A comparison of the metabolic profiles was performed to determine differences between rootstocks and to evaluate whether metabolic variation could be detected in scions grafted onto the different rootstocks. A total of 150 metabolites were identified from eight samples. Some of these metabolites were primary and secondary metabolites, including nucleosides and hormones. The largest metabolite group identified was phenolic compounds with 41 metabolites, while the smallest group was the vitamins and their derivatives which consisted of two metabolites. A comparison of metabolites found in the rootstocks and the scion grafted onto them is presented in Table 1. 
Table 1. Number of identified metabolites in rootstocks, scion, and percentage of similarities with control or rootstock.

\begin{tabular}{|c|c|c|c|c|c|c|c|c|c|c|c|c|c|c|c|c|}
\hline \multirow{4}{*}{ Group compound } & \multicolumn{16}{|c|}{ Number of identified metabolites in samples based on compound groups } \\
\hline & \multirow{2}{*}{\multicolumn{4}{|c|}{$\begin{array}{l}\text { Total identified } \\
\text { metabolites in } \\
\text { rootstock }\end{array}$}} & \multirow[b]{3}{*}{ R0 } & \multirow{2}{*}{\multicolumn{6}{|c|}{ Compared to control }} & \multirow{2}{*}{\multicolumn{5}{|c|}{ Compared to rootstock }} \\
\hline & & & & & & & & & & & & & & & & \\
\hline & R0 & $\mathbf{R} 1$ & $\mathbf{R 2}$ & $\mathbf{R 3}$ & & $\mathbf{R 1}$ & $\mathbf{R 2}$ & $\mathbf{R 3}$ & G0 & G1 & G2 & G3 & G0 & G1 & G2 & G3 \\
\hline Phenolic & 9 & 10 & 11 & 7 & 9 & 2 & 3 & 3 & 6 & 4 & 5 & 4 & 6 & 2 & 3 & 3 \\
\hline Lipids and lipid-like molecules & 19 & 22 & 21 & 9 & 19 & 16 & 16 & 9 & 12 & 12 & 15 & 9 & 12 & 13 & 17 & 7 \\
\hline Amino acids, peptides, and analogues & 16 & 13 & 14 & 18 & 16 & 12 & 11 & 12 & 12 & 9 & 13 & 12 & 12 & 9 & 13 & 15 \\
\hline Organoheterocyclic compounds & 3 & 3 & 7 & 1 & 3 & 1 & 3 & 1 & 1 & 2 & 2 & 1 & 1 & 1 & 3 & 1 \\
\hline Benzenoids and substituted deriv & 5 & 3 & 3 & 6 & 5 & 4 & 3 & 4 & 5 & 4 & 5 & 4 & 5 & 3 & 4 & 4 \\
\hline Organic acids and derivatives & 2 & 3 & 2 & 4 & 2 & 2 & 2 & 2 & 2 & 2 & 2 & 1 & 2 & 2 & 2 & 2 \\
\hline Carbo & 1 & 1 & 1 & 0 & 1 & 0 & 0 & 0 & 1 & 1 & 1 & 1 & 1 & 0 & 0 & 0 \\
\hline Alkal & 1 & 2 & 2 & 3 & 1 & 1 & 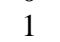 & 1 & 0 & 1 & 1 & 1 & 0 & 1 & 2 & 2 \\
\hline Orga & 1 & 2 & 2 & 1 & 1 & 1 & 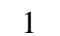 & 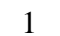 & 1 & 1 & 1 & 1 & 1 & 1 & 1 & 2 \\
\hline Nucleo & 2 & 1 & 2 & 1 & 2 & 1 & 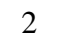 & 1 & 1 & 2 & 2 & 1 & 1 & 1 & 2 & 1 \\
\hline Organic $n$ & 2 & 3 & 3 & 3 & 2 & 2 & 2 & 2 & 1 & 2 & 1 & 1 & 1 & 2 & 1 & 2 \\
\hline Plant hormones and derivatives & 2 & 2 & 2 & 2 & 2 & 2 & 2 & 1 & 2 & 2 & 2 & 2 & 2 & 2 & 2 & 1 \\
\hline Vitamin and derivatives & 0 & 1 & 1 & 1 & 0 & 0 & 0 & 0 & 0 & 0 & 0 & 0 & 0 & 1 & 1 & 1 \\
\hline Total number of identified metabolites & 63 & 67 & 72 & 56 & 63 & 44 & 46 & 37 & 44 & 42 & 50 & 38 & 44 & 38 & 51 & 41 \\
\hline
\end{tabular}

Percentage similarity with control or rootstock

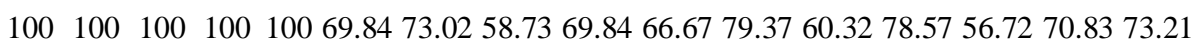

Note: R0: Tawangmangu, R1: Fortunella, R2: JC, R3: C. hystrix, G0:Tawangmangu autograft, G1: Tawangmangu on Fortunella, G2: Tawangmangu on JC, G3: Tawangmangu on $C$. hystrix

Of the rootstocks, JC had the highest similarity (73\%) with Tawangmangu, followed by Fortunella (69.8\%); the lowest similarity was found with $C$. hystrix $(58.7 \%)$. The highest similarity of the metabolite profiles with Tawangmangu of the scions grafted on to the different rootstocks was found with Tawangmangu grafted onto JC (79.4\%), followed by grafts with Fortunella $(66.7 \%)$, and the lowest was found with grafts with $C$. hystrix $(60.3 \%)$. These variations in metabolite profiles may contribute to the differences between composite plant growth and morphology. The percentage of similarity between JC and scions of Tawangmangu with JC as rootstock was $70.8 \%$, and those between Fortunella and grafts with Fortunella as rootstock was $56.7 \%$. However, in grafts produced by $C$. hystrix as rootstock, the percentage metabolite similarity was closer to the original rootstock $(73.2 \%)$ compared to scion $(60.3 \%)$. It could be argued that composite plants with vigorous growth have a high metabolic profile similarity to the scion used, and it was inversely proportional to plants experiencing dwarfing. In this case, previous studies showed that rootstock was obviously influenced the composition of plant metabolites detected in the graft's leaves (Killiny et al. 2018; Chitarra et al. 2017), fruit juice (Aslam et al. 2019; Chitarra et al. 2017; Tietel et al. 2020), and phloem sap (Tietel et al. 2020). Results of this study were in line to some degree with those previous reports. Some grafts have metabolite profiles closer to scion, but some of them were closer to rootstocks. In some cases, the characters occurring in composite plants were somewhat different from both the rootstock and scion, which was likely due to a combination or as a result of physiological interactions between scion and the rootstock (Killiny et al. 2016; Tietel et al. 2020). A study of metabolites comparisons on Citrus grafts conducted by Zhang et al. (2019) revealed that the characters of chimeras synthesized artificially by grafting could be dominant in one plant donor, but in other characters, it was closer to other donors. In the case where the metabolite profile of the Tawangmangu autograft was not more similar to Tawangmangu, the most probable cause is that the grafting process might induce a stress response in plants. This stress response might cause changes in gene expression in the autograft (Kumari et al. 2015). The alteration on gene expression has an impact on changes in plant physiological processes and metabolites produced by plants (Prodhomme et al. 2019). The physiological changes were presumably underlying the differences in metabolite profiles on autograft.

Results of this study clearly showed that the use of different rootstocks with Tawangmangu as the scion caused morphological, anatomical, and metabolic alterations in composite plants to different degrees. The most obvious changes include dwarfing or vigorous growth, changes vascular vessel size, and differences in metabolite composition.

\section{ACKNOWLEDGEMENTS}

This research was partially funded by the Ministry of Research, Technology, and Higher Education of the Republic of Indonesia for PDD Research Grants 2017 under contract number: 4606/UN31.2/DN/2017 (granted for Einstivina Nuryandani), and RTA-UGM Research Grants 2019 number 244 (granted for Siti Subandiyah). 


\section{REFERENCES}

Agus S, Eka PN. 2017. Interstock effect on the growth of mandarin cv Batu 55, tangerine cv Pontianak and lime cv Nimas propagated by grafting. RJOAS 10 (70): 239-246. DOI: 10.18551/rjoas.2017-10.34.

Albrecht U, Fiehn O, Bowman KD. 2016. Metabolic variations in different citrus rootstock cultivars associated with different responses to Huanglongbing. Plant. Physiol. Biochem. 107: 33-44. DOI: 10.1016/j.plaphy.2016.05.030.

Aslam A, Zhao S, Azam M, Lu X, He N, Li B, Dou J, Zhu H, Liu W. 2020. Comparative analysis of primary metabolites and transcriptome changes between ungrafted and pumpkin-grafted watermelon during fruit development. Peer J. 8: e8259. DOI: 10.7717/peerj.8259.

Assunção M, Canas S, Cruz S, Brazão J, Zanol GC, Eiras-Dias JE. 2016 Graft compatibility of Vitis: the role of phenolic acids and flavanols. Sci. Hortic. 207:140-145. DOI: 10.1016/j.scienta.2016.05.020

Baron D, Esteves Amaro AC, Pina A, Ferreira G. 2019. An overview of grafting re-establishment in woody fruit species. Sci. Hortic. 243: 84 91. DOI: $10.1016 /$ j.scienta.2018.08.012

Chitarra W, Perrone I, Avanzato CG, Minio A, Boccacci P, Santini D, Gilardi G, Siciliano I, Gullino ML, Delledonne M, Mannini F, Gambino G. 2017. Grapevine grafting: Scion transcript profiling and defense-related metabolites induced by rootstocks. Front. Plant Sci. 8: 1-15. DOI: 10.3389/fpls.2017.00654.

de Carvalho WS, Marinho C, Arantes M, Campbell G, Amaral BD, Cunha MD. 2018. Agronomic and Anatomical Indicators of dwarfism and graft incompatibility in citrus plants. J. Agr. Sci. 10: 263-274. DOI: 10.5539/jas.v10n9p263.

De-Miguel MD, Caballero P, Fernández-Zamudio MA. 2019. Varietal change dominates adoption of technology in Spanish citrus production. Agronomy 9: 1-15. DOI: 10.3390/agronomy9100631.

Eltayb MTA, Magid TDA, Ibrahim AA, Dirar AM. 2014. Effect of grafting rootstock on morphological changes of scions in some Acacia species. J. For. Prod. Ind.3 (1): 27-36.

Foster TM, McAtee PA, Waite CN, Boldingh HL, McGhie TK. 2017. Apple dwarfing rootstocks exhibit an imbalance in carbohydrate allocation and reduced cell growth and metabolism. Hortic Res 4: 17009. DOI: 10.1038/hortres.2017.9.

Hartmann HT, Kester DE, Davies FT, Geneve RL. 2011. Hartmann \& Kester's Plant Propagation: Principles and Practices $8^{\text {th }}$ ed. PrenticeHall, New Jersey.

He W; Wang Y; Chen Q; Sun B; Tang HR; Pan DM; Wang XR. 2018. Dissection of the mechanism for compatible and incompatible graft combinations of Citrus grandis (L.) Osbeck ('Hongmian Miyou'). Int. J. Mol. Sci. 19: 505. DOI: 10.3390/ijms19020505

Killiny N, Valim MF, Jones EJ, Hijaz F. 2018. Effect of different rootstock on the leaf metabolite profile of 'Sugar Belle' mandarin hybrid. Plant Signal Behav 13 (3): 1-4. DOI: 10.1080/15592324.2016.1249080
Kimura Y, Naeshiro M, Tominaga Y, Anai T, Komai F. 2017. Metabolite composition of grapefruit (Citrus paradisi) grown in japan depends on the growing environment and harvest period. Hortic. J. 86 (4): 543-551. DOI: 10.2503/hortj.MI-139.

Kudo H, Harada T. 2007. A graft-transmissible RNA from tomato rootstock changes leaf morphology of potato scion. HortScience 42 (2): 225-226. DOI: 10.21273/HORTSCI.42.2.225.

Kumari A, Kumar J, Kumar A, Chaudhury A, Singh SP. 2015. Grafting triggers differential responses between scion and rootstock. PLoS One 10 (4): e0124438 (1-19). DOI: 10.1371/journal.pone.0124438.

Nanda AK, Melnyk CW. 2018. The role of plant hormones during grafting. J. Plant Res.131 (1): 49-58. DOI: 10.1007/s10265-017-09945 .

Navarro L, Juarez J. 2007. Shoot-tip Grafting in vitro: Impact in the Citrus Industry and Research Application. In Khan IA (Ed) Citrus: Genetics, Breeding, And Biotechnology $1^{\text {st }}$ ed: 353-364. CAB International, Oxfordshire.

Prodhomme D, Fonayet JV, Hévin C, Franc C, Hilbert 1, de Revel G, Richard T, Ollat N, Cookson SJ. 2019. Metabolite profiling during graft union formation reveals the reprogramming of primary metabolism and the induction of stilbene synthesis at the graft interface in grapevine. BMC Plant Biol. 19 (1): 1-12. DOI: 10.1186/s12870-019-2055-9.

Ramírez-Gil JG. 2018. Avocado wilt complex disease, implications and management in Colombia. Rev. Fac Nac. Agron. Medellin 71 (2): 8525-8541. DOI: 10.15446/rfna.v71n2.66465.

Singh AK, Meetei NT, Kundu S, Salma U, and Mandal N. 2019. In vitro micrografting using three diverse indigenous rootstocks for the production of Citrus tristeza virus-free plants of Khasi mandarin. In Vitro Cell. Dev Biol Plant 55 (2): 180-189. DOI: 10.1007/s11627018-9946-6.

Tietel Z, Srivastava S, Fait A, Tel-Zur N, Carmi N, and Raveh E. 2020. Impact of scion/rootstock reciprocal effects on metabolomics of fruit juice and phloem sap in grafted Citrus reticulata. PLoS ONE 15(1): 1-17. DOI: 10.1371/journal.pone.0227192.

Vršič S, Pulko B, and Kocsis L. 2016. Effects of rootstock genotypes on compatibility, biomass, and the yield of Welschriesling. Hort. Sci. 43 (2): 92-99. DOI: 10.17221/141/2015-HORTSCI

Zhang M, Jing L, Wu Q, Zhu K, Ke F, Xu J, Zhao S, Wang G, Zhang C. 2019. Metabolite profile comparison of a graft chimera 'Hongrou Huyou' (Citrus changshan-huyou + Citrus unshiu) and its two donor plants. BMC Plant Biol 19 (582): 1-12. DOI: 10.1186/s12870-0192173-4.

Zhou K, Jerszurki D, Sadka A, Shlizerman L, Rachmilevitch S, and Ephrath J. 2018. Effects of photoselective netting on root growth and development of young grafted orange trees under semi-arid climate. Sci Hortic 238: 272-280. DOI: 10.1016/j.scienta.2018.04.054. 